\title{
Emerging Developments in
} \section{Microbiome and Microglia Research: Implications for Neurodevelopmental Disorders}

\author{
Yeonwoo Lebovitz ${ }^{1}$, Veronica M. Ringel-Scaia ${ }^{1}$, Irving C. Allen ${ }^{1,2,3 *}$ and \\ Michelle $H$. Theus ${ }^{1,2,3,4 *}$
}

${ }^{1}$ Graduate Program in Translational Biology, Medicine, and Health, Virginia Tech, Blacksburg, VA, United States, ${ }^{2}$ Department of Biomedical Sciences and Pathobiology, Virginia-Maryland College of Veterinary Medicine, Blacksburg, VA, United States, ${ }^{3}$ Department of Basic Science Education, Virginia Tech Carilion School of Medicine, Roanoke, VA, United States, ${ }^{4}$ Center for Regenerative Medicine, Virginia-Maryland College of Veterinary Medicine, Blacksburg, VA, United States

\section{OPEN ACCESS}

Edited by:

John R. Lukens,

University of Virginia, United States

Reviewed by:

Andrew MacLean,

Tulane University School of Medicine,

United States

Antonio Lucio Teixeira, University of Texas Health Science Center at Houston, United States

${ }^{*}$ Correspondence: Irving C. Allen icallen@vt.edu Michelle H. Theus mtheus@vt.edu

Specialty section: This article was submitted to

Multiple Sclerosis and

Neuroimmunology,

a section of the journal

Frontiers in Immunology

Received: 30 May 2018 Accepted: 13 August 2018 Published: 03 September 2018

Citation:

Lebovitz Y, Ringel-Scaia VM, Allen IC and Theus MH (2018) Emerging Developments in Microbiome and Microglia Research: Implications for

Neurodevelopmental Disorders.

Front. Immunol. 9:1993.

doi: 10.3389/fimmu.2018.01993
From immunology to neuroscience, interactions between the microbiome and host are increasingly appreciated as potent drivers of health and disease. Epidemiological studies previously identified compelling correlations between perinatal microbiome insults and neurobehavioral outcomes, the mechanistic details of which are just beginning to take shape thanks to germ-free and antibiotics-based animal models. This review summarizes parallel developments from clinical and preclinical research that suggest neuroactive roles for gut bacteria and their metabolites. We also examine the nascent field of microbiome-microglia crosstalk research, which includes pharmacological and genetic strategies to inform functional capabilities of microglia in response to microbial programming. Finally, we address an emerging hypothesis behind neurodevelopmental disorders, which implicates microbiome dysbiosis in the atypical programming of neuroimmune cells, namely microglia.

Keywords: autism, bacterial metabolites, gut bacteria, lactobacillus, microbiota, neurodevelopment, neuroimmune

\section{INTRODUCTION}

The various microbial ecosystems ("microbiota") and their component genes ("microbiomes") existing on and within the host body are increasingly recognized as significant contributors to a functional host immune system. Commensal microbiota consist of bacteria, fungi, viruses, and other microorganisms that make up distinct microbial ecologies of various host systems, such as the gastrointestinal tract, skin, mouth, and genitourinary tract (1). Within each physiological niche, microbial compositions can vary widely according to the environment and mutualistic functions that they may serve in conjunction with the host (2). In the gut, where microbial density is the highest, some of these functions include forming a physical barrier against infection by pathogenic microbes, acting as a bioreactor for digestion and nutrient absorption, and sensitizing the host immune system (3). The latter interaction is especially critical in early development, as the colonization of the infant gut with an initial inoculum of maternal microbiota primes the neonatal peripheral immune system $(4,5)$. 
Given the wealth of evidence depicting microbiota as a driver of early peripheral immunity, an important follow-up question remains as to whether the microbiome may also drive immune development in the brain. The neuroimmune system, primarily comprised of glial cells, is distinct from the peripheral immune system in part due to anatomical barriers and developmental sequence. Microglia, the resident macrophage-like cells in the brain, play an especially critical role in neurodevelopment through their numerous functions in patterning and wiring of the maturing brain. Accordingly, recent studies on neurodevelopmental disorders, such as autism spectrum disorders (ASD), Rett syndrome, and schizophrenia, whose complex pathologies include neuronal and synaptic dysfunction, suggest improper microglial activity as a contributor to these disorders' neurobiological and behavioral outcomes (6-8). Interestingly, additional studies suggest that microglia, not unlike peripheral macrophages, may be susceptible to microbiome changes $(9,10)$. Altogether, the demonstration of microbial influence on brain function via microglial mediators raises the possibility that manipulation of microbe-immune crosstalk represents a promising strategy for treating neurological diseases.

\section{MICROBIOME AND NEURODEVELOPMENT}

A growing number of studies pointing to distinct gut microbiome profiles among psychiatric patient populations allude to microbiota as an important corollary of disease pathology (11-14). The purported mechanisms for microbial linkages to aberrant neurobehavioral outcomes are broadly considered to be due to impaired gut-brain communication, including but not limited to those cause by cytokine imbalance, vagal nerve signaling, and hypothalamic-pituitary-adrenal (HPA) axis responses (15-17).

Disruptions to gut microbiota are also implicated in aberrant neurodevelopmental outcomes (18-20). Here, the impaired gutbrain pathways are extrapolated to include both mother and fetus, i.e., the maternal gut-fetal brain axis. Permeability of maternal gut epithelium, the placental barrier, and fetal bloodbrain barrier are potential factors of maternal gut-fetal brain communication, as are neuroactive microbial metabolites that are small enough to bypass these barriers $(5,21)$. The conceptual basis for how the maternal microbiome may drive offspring neurodevelopment is illustrated in Figure 1. Maternal skin and vaginal microbiota play a critical role in seeding the infant microbiota and were shown to contribute equally to various body site taxa in infants up to 6 weeks of age in vaginal deliveries and cesarean deliveries accompanied by active labor (22). In addition, amniotic fluid, placenta, and umbilical cord blood possess their own niche microbiomes, although the manner and extent to which these microbial communities communicate with the mother or fetus are not yet clear (23).

While the gut microbiome is constantly evolving in response to dietary and environmental changes, longitudinal sampling of infant stool during the first 3 years of life demonstrated resiliency in its ability to return to original homeostatic conditions following short periods of antibiotic usage (24). Additional studies suggest that the overall composition of the gut microbiome may remain stable across multiple decades of life (25). Interestingly, developmental shifts in gut microbial composition align with milestones in brain development, such as neuronal migration and proliferation, myelination, and synaptic pruning (Figure 2). Although these developmental correlations do not necessarily indicate a causal relationship, strong evidence from experimental models using germ-free (GF) and antibiotictreated rodents showed that the complete absence or severe reduction of gut microbiota, respectively, resulted in altered brain chemistry, transcriptional changes, and atypical behaviors compared to controls $(18,26,27)$.

Nonetheless, large-scale epidemiological studies highlight compelling correlations between certain microbiomemodifying pregnancy events and subsequent diagnoses of neurodevelopmental disorders in children. Maternal infection and antibiotic use during pregnancy are often highlighted as potential risk factors for ASD (28-30). Of the former, metaanalysis of studies reporting ASD risk of maternal infections resulted in significant associations with bacterial infections during second and third trimesters. The odds of subsequent ASD diagnosis were slightly greater than those reported for viral infections, but not as high as any maternal infection combined with a hospital visit (31). Such results also comport with numerous animal studies that used viral or bacterial components to elicit maternal immune activation and resulted in broad-based ASD- and schizophrenia-like phenotypes in the offspring, including neuroinflammation, dysregulated neural circuitry, behavioral deficits, and gene expression changes (32-36). Within the context of the mother-child dyad, these findings suggest that acute, immune insults as a result of microbial dysbiosis during pregnancy may be more influential on neurodevelopmental outcomes than chronic conditions that mainly affect the mother alone.

\section{Gut Bacteria}

Gastrointestinal issues are a common comorbidity in ASD, which remains a factor even when considering non-autistic sibling controls (37). Comparative gut microbial profiling studies in ASD suggest that, in the absence of a pathogenic infection, the lack of commensal microbes and/or microbial communities found in neurotypical counterparts may contribute to adverse health outcomes. Pyrosequencing of fecal bacteria DNA in children diagnosed with ASD determined lower abundance of gut bacteria species known to ferment complex carbohydrates, such as Prevotella, Coprococcus, and Veillonellaceae compared to non-autistic children (38). Meanwhile, other studies reported increased abundance of Bacteroides, Ruminococcus, and Sutterella in autistic children compared to controls $(39,40)$. A recent open-labeled clinical study showed that fecal microbiota transplantation resulted in mitigation of both gastrointestinal and behavioral symptoms in autistic children that corresponded with increased diversity of gut microbiota and increased abundance of previously low populations, such as Prevotella (41). Accordingly, targeted communities of commensal gut 

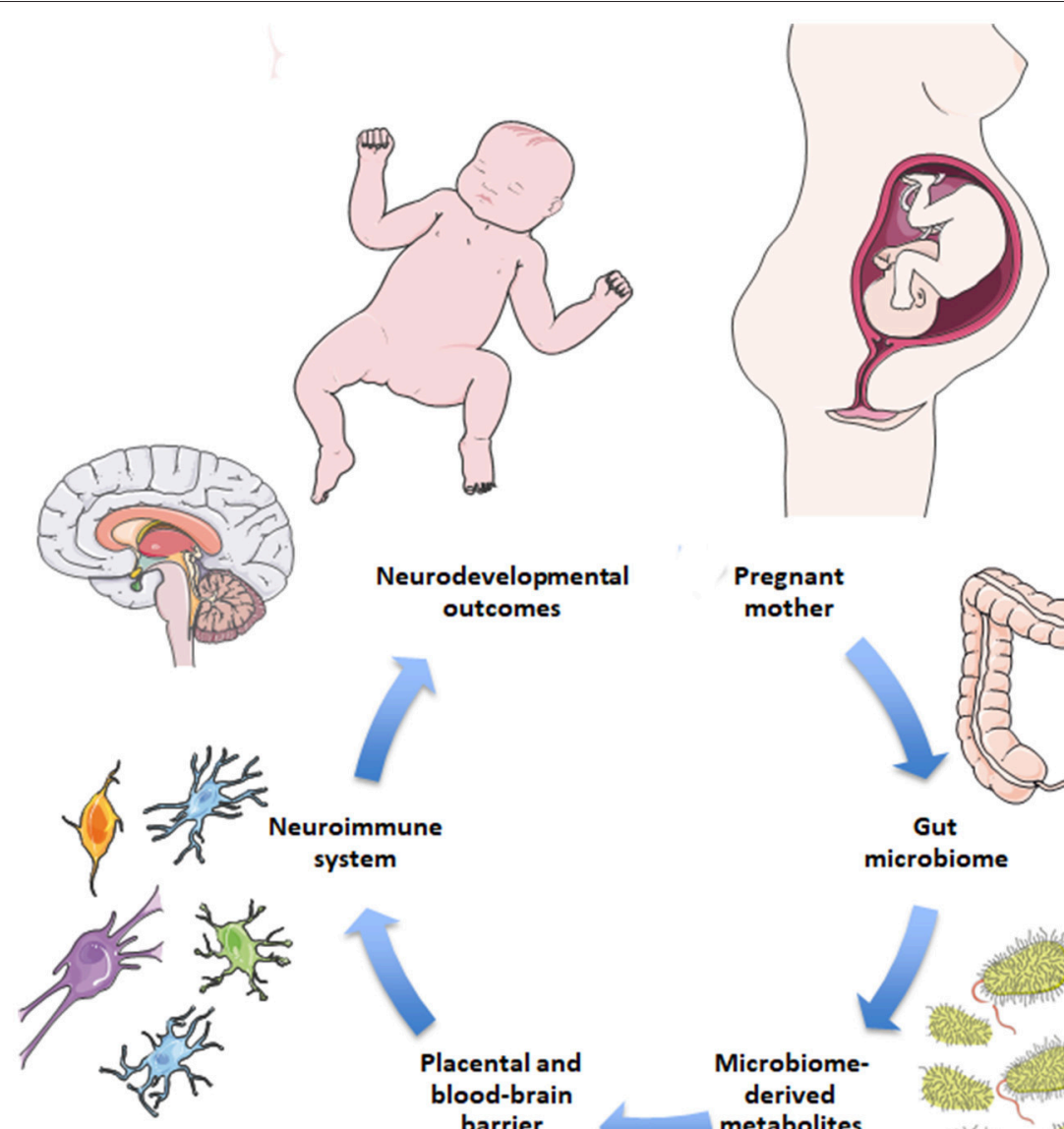

Neurodevelopmental outcomes

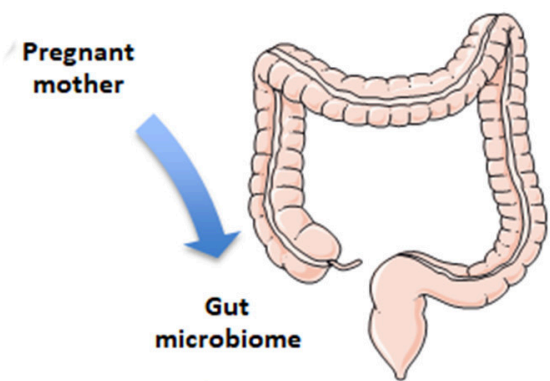

ystem
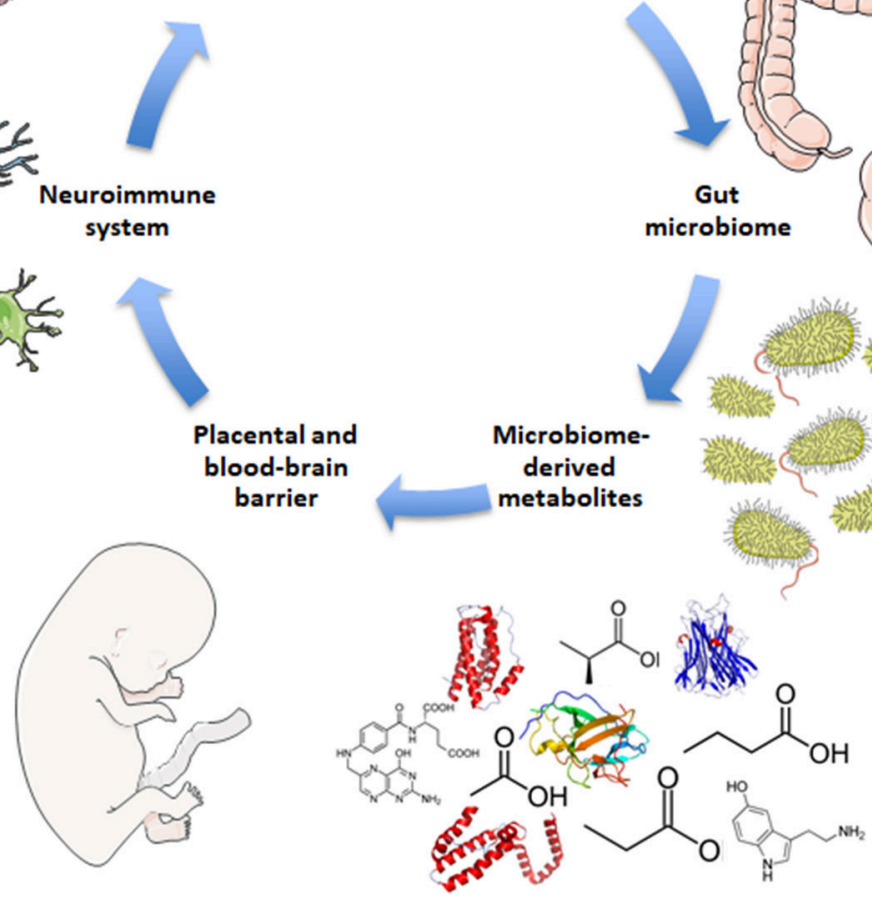

FIGURE 1 | Schematic for maternal microbiome influence on neurodevelopment. Current hypotheses propose disruptions to the maternal gut microbiome during pregnancy, such as antibiotic use, lead to altered gut microbial communities and subsequently altered levels of microbe-derived metabolites and impaired immune signaling. Microbial metabolites include neurotransmitters, neuropeptides, and short-chain fatty acids that are small enough to bypass the placental and fetal blood-brain barriers. Microbial metabolites may serve neuroactive roles through immune priming interactions with microglia in the fetal brain to potentially drive neurodevelopmental changes and behavioral outcomes later in life.

microbiota are currently under investigation as possible catalysts for gut-brain signaling. At present, research on these microbes are bacteria-specific and frequently coincide with research on probiotics. Of clinical interest are bacterial species found in maternal microflora during pregnancy and in the neonatal gut, such as Lactobacillus, Bifidobacterium, and Bacteroides, whose presence represent homeostatic conditions during healthy development (42).

Lactobacillus is a key component of a complete and diverse gut microbiome and represents a genus of bacteria naturally found in the gut of healthy mammals. The human vaginal tract microbiome is also primarily dominated by Lactobacillus spp. followed by anaerobic species from Prevotella and Sneathia spp. (42). During pregnancy, the vaginal microbiome undergoes remodeling that results in reduced diversity, increased stability, and enrichment of Lactobacilli. This is thought to protect against pathogenic infection through increased lactic acid production and decreased $\mathrm{pH}$ levels $(43,44)$. Parallel sampling of maternal and neonatal microbiota showed that the gut microbiota of vaginally-delivered infants reflects bacterial species found 
in the maternal gut microbiome, whereas cesarean-delivered infants were more likely to harbor bacteria from maternal skin microbiome, e.g., Staphylococcus, Corynebacterium, and Propionibacterium spp. (42). Meanwhile, the use of intrapartum antibiotics resulted in infant gut dysbiosis at 3 months and 12 months of age regardless of the mode of delivery (45).

As a commensal microbe, Lactobacilli in the gastrointestinal tract confer beneficial effects to digestion through lactic acid fermentation of foods (46) and prime immune cells via interactions with leukocytes in mesenteric lymph nodes and/or via dendritic cell sampling of gut lumen contents (47-49). The influence on immune system priming has been shown to have significant effects in biological and behavioral outcomes. For example, changes to HPA axis signaling and reduced corticosterone levels were observed in mice following oral administration with various Lactobacilli strains, such as $L$. rhamnosus, (16). Similarly, L. reuteri represents another wellstudied strain with reports of restoration to ventral tegmental area synaptic plasticity and oxytocin production in mice born to dams on a high fat diet (50). Meanwhile, administration of L. helveticus resulted in decreased levels of inflammatory cytokines and improved performance in spatial memory and anxiety-related behavior tasks in IL-10 $0^{-/-}$mice (51).

Given the broad evidence base supporting the molecular and physiological impact of Lactobacillus spp., the continued focus on this genus of bacteria is not surprising. Nonetheless, other bacteria, such as Bifidobacteria and Bacteroides, have also demonstrated ability to regulate immune response and behavior. For example, oral feeding of Bacteroides fragilis to weaned mice in a maternal immune activation model of autism resulted in the recovery of gut barrier proteins, Claudin- 5 and-8, and rescue of anxiety-like and stereotypic behaviors (19). These findings suggest that bacterial functionality, such as the ability to sensitize immune cells or produce bioactive metabolites, may be a better indicator of gut-brain interaction than mere taxonomy.

\section{Gut Bacterial Metabolites}

The discovery of penicillin by Alexander Fleming popularized the notion that byproducts of microbial metabolism could serve as potent chemicals (52). These metabolic byproducts, or metabolites, range broadly in terms of their molecular assembly and function. They can act as quorum sensing molecules, energy substrates, or even competitive antimicrobials against other microbes (53-55). Microbial metabolism is also one of the critical functions of the gut microbiome in maintaining host health; the mammalian digestive system is incapable of extracting many key nutrients, such as vitamins, amino acids, and energy, from diet and relies on commensal gut microbes for these tasks (56).

The most abundant products of gut bacterial metabolism are short-chain fatty acids (SCFAs), which result from bacterial fermentation of complex carbohydrates and proteins in the colon. SCFAs refer to fatty acids consisting of one to six carbon atoms, but predominantly consist of acetic acid, butyric acid, and propionic acid in the mammalian gut (57). Of the three, acetic acid (anion: acetate) makes up the largest portion of SCFA distribution in the colon, where it readily enters the circulatory system to act as a vasodilator or energy substrate for peripheral tissues (58). Radiolabeled colonic acetate has been shown to pass the blood-brain barrier to serve as an energy substrate for astrocytes, but also to preferentially accumulate in the hypothalamus where it is converted to acetylCoA leading to downstream suppression of appetite-related hormones, Neuropeptide Y (NPY) and agouti-related peptide (AgRP) $(59,60)$. Butyric acid (anion: butyrate) is an important energy substrate for colonocytes and a well-documented histone deacetylase (HDAC) inhibitor with pharmaceutical potential for neurodegenerative diseases $(61,62)$. Interestingly, exposing microglia to sodium butyrate in vitro resulted in differential inflammatory responses wherein rat primary cells, hippocampal slice cultures, and neural co-cultures (consisting of microglia, astrocytes, and neurons) resulted in an anti-inflammatory effect against LPS, but cultured murine N9 microglial cells elicited a pro-inflammatory response (63). Propionic acid (anion: propionate) appears to be the only SCFA to demonstrate adverse effects in the brain, as direct intracerebroventricular injection of propionic acid in rats yielded a wide range of autismlike neurobehavioral changes, including repetitive motion and increased markers for astrocyte and microglia immunoreactivity (GFAP and CD68, respectively) (64).

While SCFAs' best known functions are to serve as fuel for colonocytes and regulators of host metabolism, recent investigations revealed that SCFAs directly interact with the nervous system via $G$ protein-coupled receptors, GPR41 and GPR43 (or free fatty acid receptor 3 [FFAR3] and FFAR2, respectively) $(65,66)$. Previously deemed "orphan" receptors, GPR41 and GPR43 are now understood to be expressed broadly on host tissues and immune cells and are involved in the resolution of inflammatory responses (67-69). Within the brain, GPR41 is expressed at low levels in the cerebral cortex, hippocampus, caudate, and cerebellum and preferentially binds to butyrate and propionate, whereas GPR43 is expressed at moderate levels in the caudate and preferentially binds to acetate and propionate $(67,70)$. Much remains to be discovered about the signaling mechanisms of these receptors, but emerging studies point to downstream activation of immune responses, such as IgA promotion and inhibition of NF- $\kappa$ B pathway, that are specifically triggered according to the type of metabolite ligand and location of the receptor $(71,72)$.

\section{MICROBIOME AND MICROGLIA}

Microglia are primarily recognized as the resident macrophagelike cells in the brain that serve as first-responders to pathogens, apoptotic cells, and debris with the ability to secrete soluble factors that modulate inflammatory responses. Recent studies paint a more complex portrayal of these highly-motile glial cells, which have since been found ubiquitously throughout the central nervous system, including the spinal cord, with region-specific phenotypes (73-75). Microglia originate as yolk sac progenitors (Figure 2) and are purported to migrate to the brain during early prenatal development, as demonstrated through single-cell RNAseq studies $(10,76)$. Perhaps appropriate given their presence in the embryo, microglia serve numerous 
critical functions in wiring and patterning of the developing brain. Through the production of neurotrophic factors, microglia contribute to neurogenesis and guidance of sprouting vessels, as well as phagocytosing synapses and shaping neuronal circuitry $(77,78)$. The stepwise processes in which these actions occur are not yet fully clear, although recent studies form a widening picture of microglial contribution to the proper maturation of the brain.

Current hypotheses surrounding the underlying etiology of neurodevelopmental disorders focus on microglia's dual immune and trophic capacities. Neuroimaging studies of ASD patients showed hypermyelination in both left and right medial frontal cortex, hypomyelination of the left temporo-parietal junction, and decreased local and long-range functional connectivity $(79,80)$. These findings are supported by murine models of ASD, whereby impediments to microglial functions resulted in under-pruning of synapses, hypermyelination of the prefrontal cortex, and reduced long-range functional brain connectivity (81-83). In contrast, rodent models of schizophrenia allude to an over-pruning effect of dysfunctional microglia wherein pharmaceutical intervention using minocycline resulted in stalled engulfment activity and rescued behavioral deficits (8, 84, 85). Genomic analysis of psychiatric disorders indicated upregulation of astrocyte-related genes and downregulation of neuronal/microglia-related genes across ASD, schizophrenia, and bipolar disorder to further propose a shared susceptibility in neuroimmune-specific gene networks (86).

In the gastrointestinal tract, microbiota and associated metabolites have been shown to elicit both pro- and antiinflammatory peripheral immune cell responses and to control cellular proliferation and epithelial barrier integrity $(47,87-89)$. Evidence of increased blood-brain barrier disruption, altered microglia morphology, and increased microglia density in GF mice suggests that the microbiome may have a similar influence on the brain $(9,10,21)$. However, contrary to expectations, gene expression analysis of postmortem cerebral cortex and cerebellum tissues from ASD patients showed upregulation of genes associated with barrier proteins (e.g., Claudin-5 and TRiC) compared to controls; the same analysis of small intestine duodenal tissue revealed decreased expression of barrier protein-associated genes (90). Together, these data suggest that the epithelial cell barrier integrity in the gut is compromised, but barrier protein expression in the brain is increased in ASD.

The microbiome is also implicated in the neuroinflammation hypothesis underlying the ontogeny of neurodevelopmental disorders. With respect to ASD, anatomical evidence of unusual and sustained brain overgrowth in autistic children first alluded to improper cellular responses wherein the hyperproliferative stage of early neurodevelopment continues unchecked and unresolved $(91,92)$. Thus, the neuroinflammation hypothesis stipulates neonatal microbial dysbiosis leads to improper priming of the immune system, which leads to reduced synaptic pruning and brain overgrowth in ASD. Paradoxically, immunohistochemical and cytokine profiling of brain tissue and cerebrospinal fluid samples from ASD patients showed abundance of activated microglia and increased expression

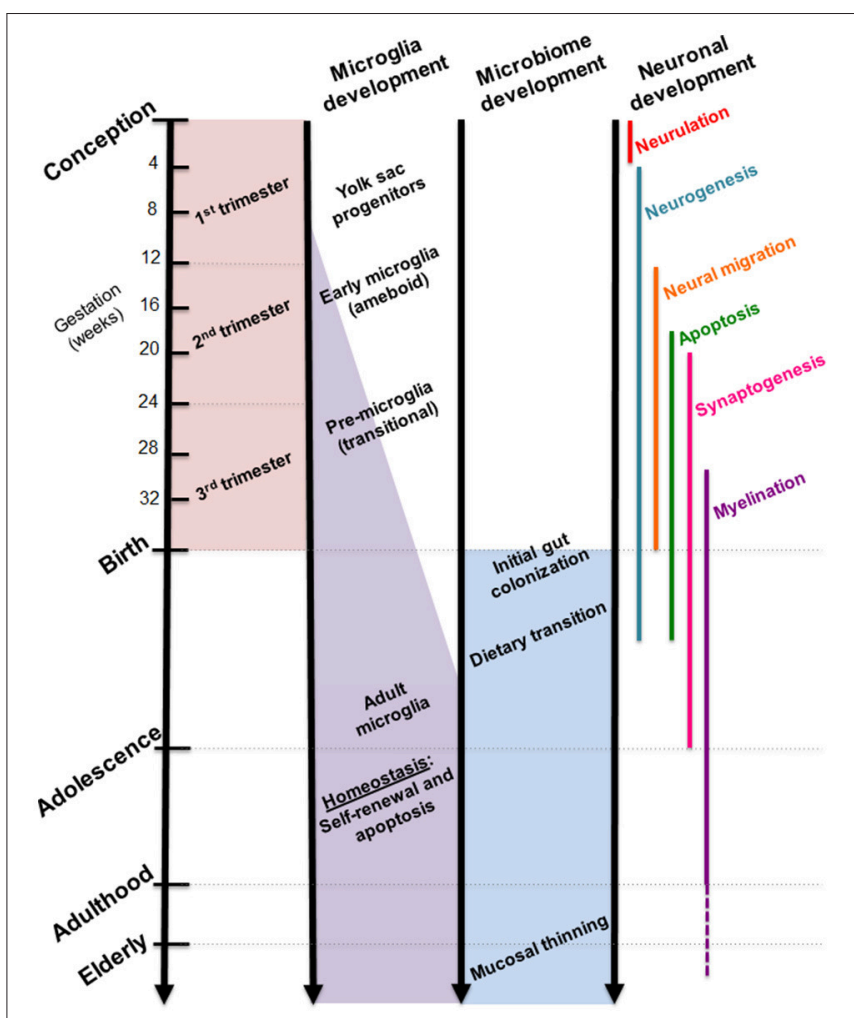

FIGURE 2 | Comparative timelines for human microglia, gut microbiome, and neuronal development. Critical stages in brain development coincide with infant gut colonization to suggest maternal microbiome may serve as an important inoculum in priming the neuroimmune system.

of macrophage chemoattractant factor-1 (MCP-1) and tumor growth factor- $\beta 1$ (TGF- $\beta 1$ ) in cerebral cortex, white matter, and cerebellum (93). Additional studies of ASD postmortem brain tissue also depicted decreased numbers of ramified, or resting state, microglia in gray and white matter and increased primed, or activated, microglia in gray matter of ASD brains compared to control samples $(7,94)$. The exact mechanism by which activated microglia neglect to phagocytose excess myelin, synapses and/or neurons, and whether this is mediated by a microbiome-immune crosstalk, is yet unknown.

Increasing evidence suggests the microbiome plays a contributing role in the function of microglia in neurodevelopment. A number of models were used to evaluate cause and effect through a reductive process that includes the use of GF models. Erny, et al., found that compared to specificpathogen free (SPF) mice, GF microglia had marked differences in mRNA expression profiles, including a reduction in genes associated with cell activation and immune signal transduction (9). While no gross or histologic abnormalities were observed in the central nervous system, GF microglia displayed an immature morphology, reduced capacity to respond to a viral infection challenge, and significant reduction in expression of regulators of microglia cell proliferation, differentiation, activation, and transformation (9). Additionally, microglia of antibiotic-treated and $\mathrm{Ffar}^{-/-}$mice that do not express the receptor gene for 
SCFA-binding also resembled a GF phenotype, which could be rescued by oral feeding of SCFAs in the former group but not the latter (9). Thus, bacteria-derived metabolites likely play a necessary and sufficient role in proper microglia development, although the mechanism(s) regarding how microbiota influence microglia-neuron interactions during development and the behavioral consequences that ensue following dysbiosis remain elusive.

\section{CONCLUSION}

The numerous microbiome-related studies across disparate scientific disciplines agree on a prevailing hypothesis that the microbiome is capable of communicating via immune, metabolic, and endocrine signals to modulate brain health and disease. The current evidence base from both human and animal studies to support this hypothesis, however, are largely correlational without definitive understanding of cause. The mechanisms by which the microbiome asserts microglial changes during neurodevelopment are also not yet known, although transgenic mice and single cell sequencing methods continue to inform molecular processes that are likely to be involved. At present, the majority of microbiome-related studies are conducted in adult mice and assume a linear direction of influence from microbiota to the host. In recognition of the microbiome's role in neurodevelopmental processes, future studies should include appropriate experimental models that

\section{REFERENCES}

1. Human Microbiome Project C. Structure, function and diversity of the healthy human microbiome. Nature (2012) 486:207-14. doi: 10.1038/nature11234

2. Segata N, Haake SK, Mannon P, Lemon KP, Waldron L, Gevers D, et al. Composition of the adult digestive tract bacterial microbiome based on seven mouth surfaces, tonsils, throat and stool samples. Genome Biol. (2012) 13:R42. doi: 10.1186/gb-2012-13-6-r42

3. Brestoff JR, Artis D. Commensal bacteria at the interface of host metabolism and the immune system. Nat Immunol. (2013) 14:676-84. doi: 10.1038/ni.2640

4. Backhed F, Roswall J, Peng Y, Feng Q, Jia H, Kovatcheva-Datchary $\mathrm{P}$, et al. Dynamics and Stabilization of the Human Gut Microbiome during the First Year of Life. Cell Host Microbe. (2015) 17:690-703. doi: 10.1016/j.chom.2015.04.004

5. Gomez de Aguero, M., Ganal-Vonarburg, S. C., Fuhrer, T., Rupp, S., Uchimura, Y., Li, H., et al. (2016). The maternal microbiota drives early postnatal innate immune development. Science 351, 1296-1302. doi: $10.1126 /$ science.aad 2571

6. Maezawa I, Jin LW. Rett syndrome microglia damage dendrites and synapses by the elevated release of glutamate. J Neurosci (2010) 30:5346-56. doi: 10.1523/JNEUROSCI.5966-09.2010

7. Lee AS, Azmitia EC, Whitaker-Azmitia PM. Developmental microglial priming in postmortem autism spectrum disorder temporal cortex. Brain Behav Immun (2017) 62:193-202. doi: 10.1016/j.bbi.2017.01.019

8. Hui CW, St-Pierre A, El Hajj H, Remy Y, Hebert SS, Luheshi GN, et al. Prenatal Immune Challenge in Mice Leads to Partly Sex-Dependent Behavioral, Microglial, and Molecular Abnormalities Associated with Schizophrenia. Front Mol Neurosci (2018) 11:13. doi: 10.3389/fnmol.2018.00013

9. Erny D, Hrabe de Angelis AL, Jaitin D, Wieghofer P, Staszewski O, David E., et al. Host microbiota constantly control maturation and function of microglia in the CNS. Nat Neurosci. (2015) 18:965-77. doi: 10.1038/nn.4030 address the maternal gut-fetal gut axis as well as the possibility of multidirectional signaling pathways.

\section{AUTHOR CONTRIBUTIONS}

YL, VR-S, IA, and MT contributed to the manuscript preparation and writing. YL and VR-S generated figures. IA and MT conducted final editing and review of the manuscript.

\section{ACKNOWLEDGMENTS}

The authors acknowledge funding from the National Institutes of Health DK105975 (IA), NS096281 (MT), and NS081623 (MT); Virginia-Maryland College of Veterinary Medicine \& Via College of Osteopathic Medicine Center for One Health Research Grant (MT, IA); Virginia-Maryland College of Veterinary Medicine Internal Research Competition (IA). Yeonwoo Lebovitz is supported through Virginia Tech Interdisciplinary Graduate Education Program in Regenerative Medicine and the Dannon Yogurt, Probiotics and the Gut Microbiome Fellowship Grant. VR-S is supported through the American Association of Immunologists Careers in Immunology Fellowship Program. Publication costs were supported by Virginia Tech Open Access Subvention Fund. The content is solely the responsibility of the authors and does not necessarily represent the official views of the NIH or any other funding agency. We apologize to any colleagues whose work was not included due to length constraints.

10. Thion MS, Low D, Silvin A, Chen J, Grisel P, Schulte-Schrepping J., et al. Microbiome influences prenatal and adult microglia in a sexspecific manner. Cell (2018) 172:500-16 e516. doi: 10.1016/j.cell.2017. 11.042

11. De Angelis M, Piccolo M, Vannini L, Siragusa S, De Giacomo A, Serrazzanetti DI, et al. Fecal microbiota and metabolome of children with autism and pervasive developmental disorder not otherwise specified. PLoS ONE (2013) 8:e76993. doi: 10.1371/journal.pone.0076993

12. Dickerson F, Severance E, Yolken R. The microbiome, immunity, and schizophrenia and bipolar disorder. Brain Behav Immun. (2017) 62:46-52. doi: 10.1016/j.bbi.2016.12.010

13. Jiang HY, Zhou YY, Zhou GL, Li YC, Yuan J, Li XH, et al. Gut microbiota profiles in treatment-naive children with attention deficit hyperactivity disorder. Behav Brain Res. (2018) 347:408-13. doi: 10.1016/j.bbr.2018.03.036

14. Hill JM, Bhattacharjee S, Pogue AI, Lukiw WJ. The gastrointestinal tract microbiome and potential link to Alzheimer's disease. Front Neurol. (2014) 5:43. doi: 10.3389/fneur.2014.00043

15. Sudo N, Chida Y, Aiba Y, Sonoda J, Oyama N, Yu XN., et al. Postnatal microbial colonization programs the hypothalamic-pituitaryadrenal system for stress response in mice. J Physiol. (2004) 558:263-75. doi: 10.1113/jphysiol.2004.063388

16. Bravo JA, Forsythe P, Chew MV, Escaravage E, Savignac HM, Dinan TG, et al. Ingestion of Lactobacillus strain regulates emotional behavior and central GABA receptor expression in a mouse via the vagus nerve. Proc Natl Acad Sci USA. (2011) 108:16050-5. doi: 10.1073/pnas.1102999108

17. Wong ML, Inserra A, Lewis MD, Mastronardi CA, Leong L, Choo J, et al. Inflammasome signaling affects anxiety- and depressive-like behavior and gut microbiome composition. Mol Psychiatry (2016) 21:797-805. doi: $10.1038 / \mathrm{mp} .2016 .46$

18. Diaz Heijtz R, Wang S, Anuar F, Qian Y, Bjorkholm B, Samuelsson A, et al. Normal gut microbiota modulates brain development and behavior. Proc Natl Acad Sci USA. (2011) 108:3047-52. doi: 10.1073/pnas.1010529108 
19. Hsiao EY, McBride SW, Hsien S, Sharon G, Hyde ER, McCue T, et al. Microbiota modulate behavioral and physiological abnormalities associated with neurodevelopmental disorders. Cell (2013) 155:1451-63. doi: 10.1016/j.cell.2013.11.024

20. Kim S, Kim H, Yim YS, Ha S, Atarashi K, Tan TG, et al. Maternal gut bacteria promote neurodevelopmental abnormalities in mouse offspring. Nature (2017b) 549:528-32. doi: 10.1038/nature23910

21. Braniste V, Al-Asmakh M, Kowal C, Anuar F, Abbaspour A, Toth M, et al. The gut microbiota influences blood-brain barrier permeability in mice. Sci Transl Med. (2014) 6:263ra158. doi: 10.1126/scitranslmed.30 09759

22. Chu DM, Ma J, Prince AL, Antony KM, Seferovic MD, Aagaard KM. Maturation of the infant microbiome community structure and function across multiple body sites and in relation to mode of delivery. Nat Med. (2017) 23:314-26. doi: $10.1038 / \mathrm{nm} .4272$

23. Jordan S, Baker B, Dunn A, Edwards S, Ferranti E, Mutic AD, et al. Maternal-Child microbiome: specimen collection, storage, and implications for research and practice. Nurs Res. (2017) 66:175-83. doi: $10.1097 /$ NNR.0000000000000201

24. Yassour M, Vatanen T, Siljander H, Hamalainen AM, Harkonen T, Ryhanen SJ, et al. Natural history of the infant gut microbiome and impact of antibiotic treatment on bacterial strain diversity and stability. Sci Transl Med. (2016) 8:343ra381. doi: 10.1126/scitranslmed.aad0917

25. Faith JJ, Guruge JL, Charbonneau M, Subramanian S, Seedorf H, Goodman $\mathrm{AL}$, et al. The long-term stability of the human gut microbiota. Science (2013) 341:1237439. doi: 10.1126/science. 1237439

26. Tochitani S, Ikeno $\mathrm{T}$, Ito $\mathrm{T}$, Sakurai $\mathrm{A}$, Yamauchi $\mathrm{T}$, Matsuzaki $\mathrm{H}$. Administration of non-absorbable antibiotics to pregnant mice to perturb the maternal gut microbiota is associated with alterations in offspring behavior. PLoS ONE (2016) 11:e0138293. doi: 10.1371/journal.pone.01 38293

27. Leclercq S, Mian FM, Stanisz AM, Bindels LB, Cambier E, Ben-Amram H, et al. Low-dose penicillin in early life induces long-term changes in murine gut microbiota, brain cytokines and behavior. Nat Commun. (2017) 8:15062. doi: $10.1038 /$ ncomms 15062

28. Atladottir HO, Henriksen TB, Schendel DE, Parner ET. Autism after infection, febrile episodes, and antibiotic use during pregnancy: an exploratory study. Pediatrics (2012) 130:e1447-54. doi: 10.1542/peds.2012-1107

29. Zerbo O, Iosif AM, Walker C, Ozonoff S, Hansen RL, Hertz-Picciotto I. Is maternal influenza or fever during pregnancy associated with autism or developmental delays? Results from the CHARGE (CHildhood Autism Risks from Genetics and Environment) study. J Autism Dev Disord. (2013) 43:25-33. doi: 10.1007/s10803-012-1540-x

30. Hisle-Gorman E, Susi A, Stokes T, Gorman G, Erdie-Lalena C, Nylund CM. Prenatal, perinatal, and neonatal risk factors of autism spectrum disorder. Pediatr Res. (2018). doi: 10.1038/pr.2018.23

31. Jiang HY, Xu LL, Shao L, Xia RM, Yu ZH, Ling ZX, et al. Maternal infection during pregnancy and risk of autism spectrum disorders: a systematic review and meta-analysis. Brain Behav Immun. (2016) 58:165-72. doi: 10.1016/j.bbi.2016.06.005

32. Fatemi SH, Reutiman TJ, Folsom TD, Huang H, Oishi K, Mori S, et al. Maternal infection leads to abnormal gene regulation and brain atrophy in mouse offspring: implications for genesis of neurodevelopmental disorders. Schizophr Res. (2008) 99:56-70. doi: 10.1016/j.schres.2007.11.018

33. Garay PA, Hsiao EY, Patterson PH, McAllister AK. Maternal immune activation causes age- and region-specific changes in brain cytokines in offspring throughout development. Brain Behav Immun. (2013) 31:54-68. doi: 10.1016/j.bbi.2012.07.008

34. Onore CE, Schwartzer JJ, Careaga M, Berman RF, Ashwood P. Maternal immune activation leads to activated inflammatory macrophages in offspring. Brain Behav Immun. (2014) 38:220-6. doi: 10.1016/j.bbi.2014.02.007

35. Sherman MP, Zaghouani H, Niklas V. Gut microbiota, the immune system, and diet influence the neonatal gut-brain axis. Pediatr Res. (2015) 77:127-35. doi: $10.1038 /$ pr.2014.161

36. Li Y, Missig G, Finger BC, Landino SM, Alexander AJ, Mokler EL, et al. Maternal and early postnatal immune activation produce dissociable effects on neurotransmission in mPFC-amygdala circuits. J Neurosci. (2018) 38:3358-72. doi: 10.1523/JNEUROSCI.3642-17.2018
37. Isaksson J, Pettersson E, Kostrzewa E, Diaz Heijtz R, Bolte S. Brief report association between autism spectrum disorder, gastrointestinal problems and perinatal risk factors within sibling pairs. J Autism Dev Disord. (2017) 47:2621-7. doi: 10.1007/s10803-017-3169-2

38. Kang DW, Park JG, Ilhan ZE, Wallstrom G, Labaer J, Adams JB, et al. Reduced incidence of Prevotella and other fermenters in intestinal microflora of autistic children. PLoS ONE (2013) 8:e68322. doi: 10.1371/journal.pone.00 68322

39. Finegold SM, Dowd SE, Gontcharova V, Liu C, Henley KE, Wolcott RD, et al. Pyrosequencing study of fecal microflora of autistic and control children. Anaerobe (2010) 16:444-53. doi: 10.1016/j.anaerobe.2010.06.008

40. Wang L, Christophersen CT, Sorich MJ, Gerber JP, Angley MT, Conlon MA. Increased abundance of Sutterella spp. and Ruminococcus torques in feces of children with autism spectrum disorder Mol Autism (2013) 4:42. doi: 10.1186/2040-2392-4-42

41. Kang DW, Adams JB, Gregory AC, Borody T, Chittick L, Fasano A, et al. Microbiota Transfer Therapy alters gut ecosystem and improves gastrointestinal and autism symptoms: an open-label study. Microbiome (2017) 5:10. doi: 10.1186/s40168-016-0225-7

42. Dominguez-Bello MG, Costello EK, Contreras M, Magris M, Hidalgo $\mathrm{G}$, Fierer $\mathrm{N}$, et al. Delivery mode shapes the acquisition and structure of the initial microbiota across multiple body habitats in newborns. Proc Natl Acad Sci USA. (2010) 107:11971-5. doi: 10.1073/pnas.10026 01107

43. McLean NW, Rosenstein IJ. Characterisation and selection of a Lactobacillus species to re-colonise the vagina of women with recurrent bacterial vaginosis. J Med Microbiol. (2000) 49:543-52. doi: 10.1099/0022-1317-49-6-543

44. Aagaard K, Riehle K, Ma J, Segata N, Mistretta TA, Coarfa C, et al. A metagenomic approach to characterization of the vaginal microbiome signature in pregnancy. PLoS ONE (2012) 7:e36466. doi: 10.1371/journal.pone.0036466

45. Azad MB, Konya T, Persaud RR, Guttman DS, Chari RS, Field CJ, et al. Impact of maternal intrapartum antibiotics, method of birth and breastfeeding on gut microbiota during the first year of life: a prospective cohort study. BJOG (2016) 123:983-93. doi: 10.1111/1471-0528.13601

46. Macfarlane GT, Macfarlane S. Bacteria, colonic fermentation, and gastrointestinal health. J AOAC Int. (2012) 95:50-60. doi: 10.5740/jaoacint.SGE_Macfarlane

47. Christensen HR, Frokiaer H, Pestka JJ. Lactobacilli differentially modulate expression of cytokines and maturation surface markers in murine dendritic cells. J Immunol. (2002) 168:171-8. doi: 10.4049/jimmunol.168.1.171

48. Fink LN, Metzdorff SB, Zeuthen LH, Nellemann C, Kristensen MB, Licht TR, et al. Establishment of tolerance to commensal bacteria requires a complex microbiota and is accompanied by decreased intestinal chemokine expression. Am J Physiol Gastrointest Liver Physiol. (2012) 302:G55-65. doi: $10.1152 /$ ajpgi.00428.2010

49. Aktas B, De Wolfe TJ, Tandee K, Safdar N, Darien BJ, Steele JL. The effect of lactobacillus casei $32 \mathrm{~g}$ on the mouse cecum microbiota and innate immune response is dose and time dependent. PLoS ONE (2015) 10:e0145784. doi: 10.1371/journal.pone.0145784

50. Buffington SA, Di Prisco GV, Auchtung TA, Ajami NJ, Petrosino JF, Costa-Mattioli M. Microbial reconstitution reverses maternal dietinduced social and synaptic deficits in offspring. Cell (2016) 165:1762-75. doi: 10.1016/j.cell.2016.06.001

51. Ohland CL, Kish L, Bell H, Thiesen A, Hotte N, Pankiv E, et al. Effects of Lactobacillus helveticus on murine behavior are dependent on diet and genotype and correlate with alterations in the gut microbiome. Psychoneuroendocrinology (2013) 38:1738-47. doi: 10.1016/j.psyneuen.2013.02.008

52. Fleming A. On the antibacterial action of cultures of a penicillium, with special reference to their use in the isolation of B. influenzæ Br J Exp Pathol. (1929) 10:226-36.

53. Chow AW, Jewesson PJ. Pharmacokinetics and safety of antimicrobial agents during pregnancy. Rev Infect Dis. (1985) 7:287-313. doi: 10.1093/clinids/7.3.287

54. Li G., and Young KD. Indole production by the tryptophanase TnaA in Escherichia coli is determined by the amount of exogenous tryptophan. Microbiology (2013) 159:402-10. doi: 10.1099/mic.0.064139-0 
55. Biggs MB, Medlock GL, Moutinho TJ, Lees HJ, Swann JR, Kolling GL, et al. Systems-level metabolism of the altered Schaedler flora, a complete gut microbiota. ISME J. (2017) 11:426-38. doi: 10.1038/ismej.2016.130

56. Velagapudi VR, Hezaveh R, Reigstad CS, Gopalacharyulu P, Yetukuri L, Islam S, et al. The gut microbiota modulates host energy and lipid metabolism in mice. J Lipid Res. (2010) 51:1101-12. doi: 10.1194/jlr.M0 02774

57. Macfarlane S, Macfarlane GT. Regulation of short-chain fatty acid production. Proc Nutr Soc. (2003) 62:67-72. doi: 10.1079/PNS2002207

58. Bergman EN. Energy contributions of volatile fatty acids from the gastrointestinal tract in various species. Physiol Rev. (1990) 70:567-90. doi: 10.1152/physrev.1990.70.2.567

59. Wyss MT, Magistretti PJ, Buck A, Weber B. Labeled acetate as a marker of astrocytic metabolism. J Cereb Blood Flow Metab. (2011) 31:1668-74. doi: $10.1038 /$ jcbfm.2011.84

60. Frost G, Sleeth ML, Sahuri-Arisoylu M, Lizarbe B, Cerdan S, Brody L, et al. The short-chain fatty acid acetate reduces appetite via a central homeostatic mechanism. Nat Commun. (2014) 5:3611. doi: 10.1038/ncomms4611

61. Ferrante RJ, Kubilus JK, Lee J, Ryu H, Beesen A, Zucker B, et al. Histone deacetylase inhibition by sodium butyrate chemotherapy ameliorates the neurodegenerative phenotype in Huntington's disease mice. J Neurosci. (2003) 23:9418-27. doi: 10.1523/JNEUROSCI.23-28-09418.2003

62. Govindarajan N, Agis-Balboa RC, Walter J, Sananbenesi F, Fischer A. Sodium butyrate improves memory function in an Alzheimer's disease mouse model when administered at an advanced stage of disease progression. J Alzheimers Dis. (2011) 26:187-97. doi: 10.3233/JAD-2011-110080

63. Huuskonen J, Suuronen T, Nuutinen T, Kyrylenko S, Salminen A. Regulation of microglial inflammatory response by sodium butyrate and short-chain fatty acids. $\mathrm{Br}$ J Pharmacol. (2004) 141:874-80. doi: 10.1038/sj.bjp.07 05682

64. MacFabe DF, Cain DP, Rodriguez-Capote K, Franklin AE, Hoffman JE, Boon F, et al. Neurobiological effects of intraventricular propionic acid in rats: possible role of short chain fatty acids on the pathogenesis and characteristics of autism spectrum disorders. Behav Brain Res. (2007) 176:14969. doi: 10.1016/j.bbr.2006.07.025

65. Kimura I, Inoue D, Maeda T, Hara T, Ichimura A, Miyauchi S, et al. Shortchain fatty acids and ketones directly regulate sympathetic nervous system via G protein-coupled receptor 41 (GPR41). Proc Natl Acad Sci USA. (2011) 108:8030-5. doi: 10.1073/pnas.1016088108

66. Nohr MK, Pedersen MH, Gille A, Egerod KL, Engelstoft MS, Husted AS, et al. GPR41/FFAR3 and GPR43/FFAR2 as cosensors for short-chain fatty acids in enteroendocrine cells vs FFAR3 in enteric neurons and FFAR2 in enteric leukocytes. Endocrinology (2013) 154:3552-64. doi: 10.1210/en. 2013-1142

67. Brown AJ, Goldsworthy SM, Barnes AA, Eilert MM, Tcheang L, Daniels D, et al. The Orphan G protein-coupled receptors GPR41 and GPR43 are activated by propionate and other short chain carboxylic acids. J Biol Chem. (2003) 278:11312-9. doi: 10.1074/jbc.M211609200

68. Maslowski KM, Vieira AT, Ng A, Kranich J, Sierro F, Yu D, et al. Regulation of inflammatory responses by gut microbiota and chemoattractant receptor GPR43. Nature (2009) 461:1282-6. doi: 10.1038/nature08530

69. Haghikia A, Jorg S, Duscha A, Berg J, Manzel A, Waschbisch A, et al. Dietary fatty acids directly impact central nervous system autoimmunity via the small intestine. Immunity (2015) 43:817-29. doi: 10.1016/j.immuni.2015. 09.007

70. Uhlen M, Fagerberg L, Hallstrom BM, Lindskog C, Oksvold P, Mardinoglu A, et al. Proteomics. Tissue-based map of the human proteome Science (2015) 347:1260419. doi: 10.1126/science.1260419

71. Lee SU, In HJ, Kwon MS, Park BO, Jo M, Kim MO, et al. $\beta$-Arrestin 2 Mediates G Protein-Coupled Receptor 43 Signals to Nuclear Factor- $\kappa$ B. Biol Pharmaceut Bull. (2013) 36:1754-9. doi: 10.1248/bpb.b13-00312

72. Wu W, Sun M, Chen F, Cao AT, Liu H, Zhao Y, et al. Microbiota metabolite short-chain fatty acid acetate promotes intestinal IgA response to microbiota which is mediated by GPR43. Mucosal Immunol. (2017) 10:94656. doi: $10.1038 / \mathrm{mi} .2016 .114$

73. Zhu P, Hata R, Cao F, Gu F, Hanakawa Y, Hashimoto K, et al. Ramified microglial cells promote astrogliogenesis and maintenance of neural stem cells through activation of Stat3 function. FASEB J. (2008) 22:3866-77. doi: 10.1096/fj.08-105908

74. Caldero J, Brunet N, Ciutat D, Hereu M, Esquerda JE. Development of microglia in the chick embryo spinal cord: implications in the regulation of motoneuronal survival and death. J Neurosci Res. (2009) 87:2447-66. doi: 10.1002/jnr.22084

75. De Biase LM, Schuebel KE, Fusfeld ZH, Jair K, Hawes IA, Cimbro R, et al. Local cues establish and maintain region-specific phenotypes of basal ganglia microglia. Neuron (2017) 95:341-56:e346. doi: 10.1016/j.neuron.2017. 06.020

76. Matcovitch-Natan O, Winter DR, Giladi A, Vargas Aguilar S, Spinrad A, Sarrazin S, et al. Microglia development follows a stepwise program to regulate brain homeostasis. Science (2016) 353:aad8670. doi: 10.1126/science. aad 8670

77. Shigemoto-Mogami Y, Hoshikawa K, Goldman JE, Sekino Y, Sato K. Microglia enhance neurogenesis and oligodendrogenesis in the early postnatal subventricular zone. J Neurosci. (2014) 34:2231-43. doi: 10.1523/JNEUROSCI.1619-13.2014

78. Weinhard L, di Bartolomei G, Bolasco G, Machado P, Schieber NL, Neniskyte $U$, et al. Microglia remodel synapses by presynaptic trogocytosis and spine head filopodia induction. Nat Commun. (2018) 9:1228. doi: 10.1038/s41467-018-03566-5

79. Carmody DP, Lewis M. Regional white matter development in children with autism spectrum disorders. Dev Psychobiol/ (2010) 52:755-63. doi: 10.1002/dev.20471

80. Khan S, Gramfort A, Shetty NR, Kitzbichler MG, Ganesan S, Moran JM, et al. Local and long-range functional connectivity is reduced in concert in autism spectrum disorders. Proc Natl Acad Sci USA. (2013) 110:3107-12. doi: 10.1073/pnas. 1214533110

81. Zhan Y, Paolicelli RC, Sforazzini F, Weinhard L, Bolasco G, Pagani F, et al. Deficient neuron-microglia signaling results in impaired functional brain connectivity and social behavior. Nat Neurosci. (2014) 17:400-6. doi: 10.1038/nn.3641

82. Hoban AE, Stilling RM, Ryan FJ, Shanahan F, Dinan TG, Claesson MJ, et al. Regulation of prefrontal cortex myelination by the microbiota. Transl Psychiatry (2016) 6:e774. doi: 10.1038/tp.2016.42

83. Kim HJ, Cho MH, Shim WH, Kim JK, Jeon EY, Kim DH, et al. Deficient autophagy in microglia impairs synaptic pruning and causes social behavioral defects. Mol Psychiatry (2017a) 22:1576-84. doi: 10.1038/mp. 2016.103

84. Giovanoli S, Engler H, Engler A, Richetto J, Feldon J, Riva MA, et al. Preventive effects of minocycline in a neurodevelopmental two-hit model with relevance to schizophrenia. Transl Psychiatry (2016) 6:e772. doi: $10.1038 /$ tp. 2016.38

85. Mallya AP, Wang HD, Lee HNR, and Deutch AY. Microglial pruning of synapses in the prefrontal cortex during adolescence. Cereb Cortex (2018). bhy061-bhy061. doi: 10.1093/cercor/bhy061

86. Gandal MJ, Haney JR, Parikshak NN, Leppa V, Ramaswami G, Hartl C, et al. Shared molecular neuropathology across major psychiatric disorders parallels polygenic overlap. Science (2018) 359:693-7. doi: 10.1126/science. aad6469

87. Pull SL, Doherty JM, Mills JC, Gordon JI, Stappenbeck TS. Activated macrophages are an adaptive element of the colonic epithelial progenitor niche necessary for regenerative responses to injury. Proc Natl Acad Sci USA. (2005) 102:99-104. doi: 10.1073/pnas.0405979102

88. Furusawa Y, Obata Y, Fukuda S, Endo TA, Nakato G, Takahashi D, et al Commensal microbe-derived butyrate induces the differentiation of colonic regulatory T cells. Nature (2013) 504:446-50. doi: 10.1038/nature12721

89. Hayashi A, Sato T, Kamada N, Mikami Y, Matsuoka K, Hisamatsu T, et al. A single strain of Clostridium butyricum induces intestinal IL-10-producing macrophages to suppress acute experimental colitis in mice. Cell Host Microbe. (2013) 13:711-22. doi: 10.1016/j.chom.2013.05.013

90. Fiorentino M, Sapone A, Senger S, Camhi SS, Kadzielski SM, Buie TM, et al. Blood-brain barrier and intestinal epithelial barrier alterations in autism spectrum disorders. Mol Autism (2016) 7:49. doi: 10.1186/s13229-016-0110-Z

91. Courchesne E, Karns CM, Davis HR, Ziccardi R, Carper RA, Tigue ZD, et al. Unusual brain growth patterns in early life in patients with autistic 
disorder: an MRI study. Neurology (2001) 57:245-54. doi: 10.1212/WNL. 57.2.245

92. Courchesne E, Carper R, Akshoomoff N. Evidence of brain overgrowth in the first year of life in autism. JAMA (2003) 290:337-44. doi: 10.1001/jama.290.3.337

93. Vargas DL, Nascimbene C, Krishnan C, Zimmerman AW, Pardo CA. Neuroglial activation and neuroinflammation in the brain of patients with autism. Ann Neurol. (2005) 57:67-81. doi: 10.1002/ana.20315

94. Smith PM, Howitt MR, Panikov N, Michaud M, Gallini CA, Bohlooly YM, et al. The microbial metabolites, short-chain fatty acids, regulate colonic Treg cell homeostasis. Science (2013) 341:569-73. doi: 10.1126/science.1241165
Conflict of Interest Statement: The authors declare that the research was conducted in the absence of any commercial or financial relationships that could be construed as a potential conflict of interest.

Copyright $\odot 2018$ Lebovitz, Ringel-Scaia, Allen and Theus. This is an open-access article distributed under the terms of the Creative Commons Attribution License (CC $B Y)$. The use, distribution or reproduction in other forums is permitted, provided the original author(s) and the copyright owner(s) are credited and that the original publication in this journal is cited, in accordance with accepted academic practice. No use, distribution or reproduction is permitted which does not comply with these terms. 